Check for updates

Cite this: RSC Adv., 2017, 7, 20591

Received 5th December 2016

Accepted 29th March 2017

DOI: 10.1039/c6ra27773

rsc.li/rsc-advances

\section{A diarylethene-based "on-off-on" fluorescence sensor for the sequential recognition of mercury and cysteine $\uparrow$}

\author{
Gang Li, Lele Ma, Gang Liu, ${ }^{*}$ Congbin Fan (D) and Shouzhi Pu* \\ A novel photochromic diarylethene with a quinoline unit was synthesized with multi-controllable \\ fluorescence switching properties, which could be induced by light, mercury $\left(\mathrm{Hg}^{2+}\right)$ and cysteine (Cys). \\ Because the diarylethene displayed obvious fluorescence quenching with $\mathrm{Hg}^{2+}$ and the fluorescence \\ was recovered to its original state evidently with Cys, it could sequentially recognize $\mathrm{Hg}^{2+}$ and Cys. \\ Additionally, a logic circuit was constructed with the fluorescence intensity at $468 \mathrm{~nm}$ as output, and the \\ combined stimuli of light and chemicals as inputs.
}

\section{Introduction}

As a hazardous chemical in the environment from a variety of natural and anthropogenic sources, ${ }^{1,2}$ the mercury ion $\left(\mathrm{Hg}^{2+}\right)$ is a caustic and carcinogenic material with high cellular toxicity ${ }^{3}$ because it accumulates in the human body and a very small amount can cause serious diseases, such as cardiovascular disease, serious cognitive and motion disorders, Minamata disease and coronary heart disease. ${ }^{4-9}$ Therefore, monitoring $\mathrm{Hg}^{2+}$ in the environment has received increasing interest. Currently, various techniques and protocols, such as atomic absorption spectrometry, inductively coupled plasma, atomic emission spectroscopy, and capillary electrophoresis have been well developed and utilized to monitor $\mathrm{Hg}^{2+} \cdot{ }^{10-13}$ However, most of these methods are still limited by complex instruments and complicated procedures with high cost, or low sensitivity and low selectivity. However, fluorescent sensors are very simple and sensitive in the detection of metal ions or harmful pollutants in the environment. Therefore, considerable efforts have been made to develop fluorescent molecular chemosensors for $\mathrm{Hg}^{2+}{ }^{24-22}$

As a small molecular weight biothiol, cysteine (Cys) plays a prominent role in various critical biological systems, such as metabolic processes, biocatalysis and detoxifications of xenobiotics. ${ }^{23-27}$ However, $\mathrm{Hg}^{2+}$ ion can bond to Cys through $\mathrm{Hg}-\mathrm{S}$ to cause many health problems, ${ }^{28-30}$ such as slowed growth in children, liver damage, loss of muscle and fat, skin lesions and weakness. ${ }^{31}$ On other hand, high levels of Cys in living systems also cause many human diseases, including developmental

Jiangxi Key Laboratory of Organic Chemistry, Jiangxi Science and Technology Normal University, Nanchang, Jiangxi 330013, PR China. E-mail: pushouzhi@tsinghua.org.cn; Fax: +86-791-83831996; Tel: +86-791-83831996

$\dagger$ Electronic supplementary information (ESI) available. See DOI: 10.1039/c6ra27773j retardation, cardiovascular, osteoporosis, Alzheimer's disease, etc. ${ }^{32}$ Therefore, it is very important to detect Cys and $\mathrm{Hg}^{2+}$ in biological systems. Up to present, detection of $\mathrm{Hg}^{2+}$ and Cys was mainly based on photochromic materials with dual functionalities. ${ }^{33-36}$ Among these various photochromic compounds, diarylethenes are one of the most promising photo-switchable molecules with excellent photochemical reactivity, thermal stability, fatigue resistance ${ }^{37-40}$ and fluorescence. ${ }^{41-43}$ For example, Tian and his co-workers have reported two photochromic diarylethene-based chemosensors with excellent optical properties to distinguish $\mathrm{Hg}^{2+}$ in acetonitrile. ${ }^{44}$ We also synthesized a photochromic diarylethene with a formyl group. Because of the interaction between the formyl group of its ringclosed isomer with Cys, there was a notable change in its absorption spectrum with an evident color change from blue to pale yellow if Cys was added. ${ }^{45}$ However, all of these reports were focused on recognizing $\mathrm{Hg}^{2+}$ and Cys individually.

In this study, we designed and synthesized a new photochromic diarylethene with a quinoline unit, which could sequentially recognize $\mathrm{Hg}^{2+}$ and Cys efficiently. Compared with previously reported results, this method was more feasible, economic, convenient and significant. The fluorescence of the diarylethene was quenched in the presence of $\mathrm{Hg}^{2+}$ in tetrahydrofuran. When a certain amount of Cys was subsequently added, the fluorescence was enhanced and restored to almost the intensity before quenching.

\section{Experimental}

\section{General methods}

NMR spectra were recorded on Bruker AV400 (400 MHz) spectrometer with $\mathrm{CDCl}_{3}$ as the solvent and tetramethylsilane (TMS) as the internal standard. Mass spectra were measured on a Bruker AmaZon SL Ion Trap Mass spectrometer. IR spectra were recorded on a Bruker Vertex-70 spectrometer. Melting 
point was measured on a WRS-1B melting point apparatus. The absorption spectra were measured on an Agilent $8453 \mathrm{UV} / \mathrm{Vis}$ spectrophotometer. Photoirradiation was carried out with an SHG-200 UV lamp, CX-21 ultraviolet fluorescence analysis cabinet and a BMH-250 visible lamp. Light of appropriate wavelength was isolated through different light filters. Fluorescence spectra were recorded on a Hitachi F-4600 fluorescence spectrophotometer. The fluorescence quantum yield was measured on an Absolute PL Quantum Yield Spectrometer QY C11347-11. All inorganic salts $\left(\mathrm{Hg}\left(\mathrm{ClO}_{4}\right)_{2} \cdot 6 \mathrm{H}_{2} \mathrm{O}, \mathrm{Cd}\left(\mathrm{NO}_{3}\right)_{2}\right.$ $\cdot 4 \mathrm{H}_{2} \mathrm{O}, \quad \mathrm{Zn}\left(\mathrm{NO}_{3}\right)_{2} \cdot 6 \mathrm{H}_{2} \mathrm{O}, \quad \mathrm{Mg}\left(\mathrm{NO}_{3}\right)_{2} \cdot 6 \mathrm{H}_{2} \mathrm{O}, \quad \mathrm{Ca}\left(\mathrm{NO}_{3}\right)_{2} \cdot 4 \mathrm{H}_{2} \mathrm{O}$, $\mathrm{Ba}\left(\mathrm{NO}_{3}\right)_{2}, \quad \mathrm{Cr}\left(\mathrm{NO}_{3}\right)_{3} \cdot 9 \mathrm{H}_{2} \mathrm{O}, \quad \mathrm{Al}\left(\mathrm{NO}_{3}\right)_{3} \cdot 9 \mathrm{H}_{2} \mathrm{O}, \quad \mathrm{Ni}\left(\mathrm{NO}_{3}\right)_{2} \cdot 6 \mathrm{H}_{2} \mathrm{O}$, $\mathrm{MnCl}_{2} \cdot 4 \mathrm{H}_{2} \mathrm{O}, \quad \mathrm{Co}\left(\mathrm{NO}_{3}\right)_{2} \cdot 6 \mathrm{H}_{2} \mathrm{O}, \quad \mathrm{Cu}\left(\mathrm{NO}_{3}\right)_{2} \cdot 3 \mathrm{H}_{2} \mathrm{O}, \quad \mathrm{Sr}\left(\mathrm{NO}_{3}\right)_{2}$, $\mathrm{Pb}\left(\mathrm{NO}_{3}\right)_{2}, \mathrm{Fe}\left(\mathrm{NO}_{3}\right)_{3} \cdot 9 \mathrm{H}_{2} \mathrm{O}$ and $\mathrm{KCl}$ ) and amino-acids (cysteine (Cys), glycine (Gly), alanine (Ala), valine (Val), leucine (Leu), isoleucine (Ile), phenylalanine (Phe), proline (Pro), tryptophan (Try), serine (Ser), tyrosine (Tyr), glutamine (Glu), threonine (Thr), glutamic acid (Glu), lysine (Lys), arginine (Arg), histidine (His)) were purchased and used without further purification. All metal ions and amino-acids were dissolved $\left(0.1 \mathrm{~mol} \mathrm{~L}^{-1}\right)$ in distilled water. All other solvents used were of spectro-grade and purified through distillation prior to use.

\section{Synthesis of 10}

The synthetic route of 1-(2-methyl-3-benzothiophenyl)-2-\{2methyl-5-(4-pheny)-(2-benzoylquinolines-8-benzothiazole)-3thienyl\}-perfluorocyclopentene (10) was shown in Fig. 1. The intermediate 2 was synthesized according to literature. ${ }^{46}$ Synthesis of 1-(2-methyl-3-benzothiophenyl)-2-\{2-methyl-5phenyl-4-(2-formylquinoline-8-methoxyl)-3-thienyl $\}$ perfluorocyclopentene (3).

To a compound $2(0.58 \mathrm{~g}, 1.00 \mathrm{mmol})$ solution in anhydrous acetonitrile $(30 \mathrm{~mL}), 8$-hydroxyquinoline-2-carboxaldehyde $(0.16 \mathrm{~g}, 0.90 \mathrm{mmol})$ and $\mathrm{K}_{2} \mathrm{CO}_{3}(0.33 \mathrm{~g}, 2.00 \mathrm{mmol})$ were added with continuously stirring. After 6 hours of refluxing, the mixture was cooled to room temperature and concentrated under vacuum. The crude product was purified through column chromatography on silica gel with petroleum ether/ethyl acetate $(\mathrm{v} / \mathrm{v}=6 / 1)$ as the eluent to afford compound 3 as a pale pink solid. The yield was 70\%. Mp 340-342 K. ${ }^{1} \mathrm{H} \mathrm{NMR}\left(\mathrm{CDCl}_{3}, 400\right.$ $\mathrm{MHz}), \delta(\mathrm{ppm}) 1.93(\mathrm{~s}, 3 \mathrm{H}), 2.30(\mathrm{~s}, 3 \mathrm{H}), 5.47$ (s, 2H), 7.15 (t, 2H, $=8.0 \mathrm{~Hz}), 7.30-7.36(\mathrm{~m}, 2 \mathrm{H}), 7.44-7.49(\mathrm{~m}, 3 \mathrm{H}), 7.52-7.57(\mathrm{~m}$, $4 \mathrm{H}), 7.73(\mathrm{~d}, 1 \mathrm{H}, J=8.0 \mathrm{~Hz}), 8.08(\mathrm{~d}, 1 \mathrm{H}, J=8.4 \mathrm{~Hz}), 8.29(\mathrm{~d}, 1 \mathrm{H}$, $J=7.8 \mathrm{~Hz}), 10.33$ (s, 1H).

Synthesis of 1-(2-methyl-3-benzothiophenyl)-2-\{2-methyl-5phenyl-4-(2-formylquinoline-8-benzothiazole)-3-thienyl $\}$ perfluorocyclopentene (10).

Compound 3 (0.34 g, $0.5 \mathrm{mmol}$ ) and 2-aminothiophenol $(0.06 \mathrm{~g}, 0.5 \mathrm{mmol})$ were dissolved in $5 \mathrm{~mL}$ of ethanol. After the

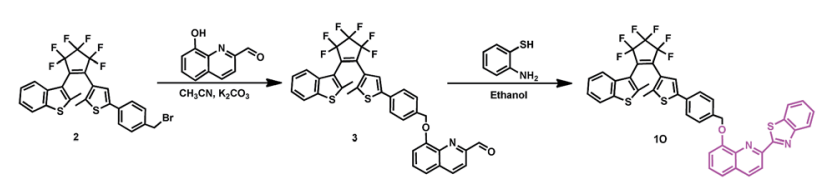

Fig. 1 Synthetic route for 10. reaction mixture was refluxed for 6 hours, a light purple powder crude product appeared. Then, the reaction mixture was cooled to room temperature, washed with cold ethanol and dried in air. The yield was $(0.31 \mathrm{~g}) 80 \%$. Mp 438-440 K. ${ }^{1} \mathrm{H} \mathrm{NMR}\left(\mathrm{CDCl}_{3}, 400\right.$ $\mathrm{MHz}), \delta(\mathrm{ppm}) 1.93$ (s, 3H), 2.31 (s, 3H), 5.46 (s, 2H), 7.13-7.21 (m, 1H), $7.24(\mathrm{~s}, 1 \mathrm{H}), 7.30-7.40(\mathrm{~m}, 3 \mathrm{H}), 7.47-7.51(\mathrm{~m}, 2 \mathrm{H}), 7.53-$ $7.59(\mathrm{~m}, 4 \mathrm{H}), 7.67(\mathrm{~d}, 2 \mathrm{H}, J=8.0 \mathrm{~Hz}), 7.75(\mathrm{~d}, 1 \mathrm{H}, J=7.7 \mathrm{~Hz}), 8.02$ $(\mathrm{d}, 1 \mathrm{H}, J=7.7 \mathrm{~Hz}), 8.14(\mathrm{~d}, 1 \mathrm{H}, J=8.1 \mathrm{~Hz}), 8.30(\mathrm{~d}, 1 \mathrm{H}, J=8.5$ $\mathrm{Hz}), 8.53(\mathrm{~d}, 1 \mathrm{H}, J=8.6 \mathrm{~Hz}) .{ }^{13} \mathrm{C} \mathrm{NMR}\left(\mathrm{CDCl}_{3}, 100 \mathrm{MHz}\right), \delta(\mathrm{ppm})$ $14.82,14.89,71.06,112.08,118.73,120.35,120.49$, 122.06, $122.09,122.13,122.18,122.57,123.77,124.51,124.95,125.19$, 125.58, 125.73, 125.84, 126.27, 127.70, 127.92, 130.36, 132.78, 136.60, 136.97, 137.04, 138.22, 140.45, 141.58, 141.69, 142.49, 150.21, 154.46. ${ }^{19} \mathrm{~F}$ NMR (DMSO, $\left.376 \mathrm{MHz}\right), \delta$ (ppm) -130.15 (1F), -128.96 (1F), -108.29 (1F), -106.88 (1F), -106.36 (2F). (Fig. S1†) IR (KBr, $\left.\nu, \mathrm{cm}^{-1}\right): 522,724,839,1052,1190,1272$, 1379, 1447, 1561. (Fig. S2†) LRMS: $m / z 807.0[\mathrm{M}+\mathrm{Na}]^{+}$.

\section{Results and discussion}

\section{Photochromism and fluorescence of 10}

The photochromic and fluorescent behaviors of 10 were studied in THF solution $\left(2.0 \times 10^{-5} \mathrm{~mol} \mathrm{~L}^{-1}\right)$ at room temperature, its absorption spectral, fluorescence spectral and color changes were induced by alternating irradiation with $297 \mathrm{~nm}$ UV light and visible light $(\lambda>500 \mathrm{~nm}$ ) (Fig. 2). As shown in Fig. 2A, the absorption maximum of 10 was at $298 \mathrm{~nm}$ due to its $\pi-\pi *$ transition. ${ }^{47,48}$ Upon the irradiation with $297 \mathrm{~nm}$ UV light, a new absorption band centered at $548 \mathrm{~nm}$ emerged due to the formation of the closed-ring isomer $\mathbf{1 C}$ of $\mathbf{1 0}$ with larger $\pi$ electron delocalization in the molecule, which was accompanied with a color change from colorless to purple. After 5 minutes of irradiation with $297 \mathrm{~nm}$ UV light, the photocyclization reaction reached a photostationary state (PSS), and the photoconversion ratio from the openring isomer 10 to the closed-ring isomer 1C was $84 \%$ based on the HPLC analysis. (Fig. S3 $\dagger$ ) The cyclization and cycloreversion quantum yield of the diarylethene were 0.34 and 0.027 , respectively, with 1,2bis(2-methyl-5-phenyl-3-thienyl)-perfluorocyclopentene as the reference. ${ }^{\mathbf{4}}$ Reversely, the absorption spectrum of $\mathbf{1 C}$ with purple solution could be completely bleached to the initial state of 10 upon the visible light irradiation $(\lambda>500 \mathrm{~nm})$. Fig. $2 \mathrm{~B}$ showed the emission spectral changes of $\mathbf{1 0}$ upon
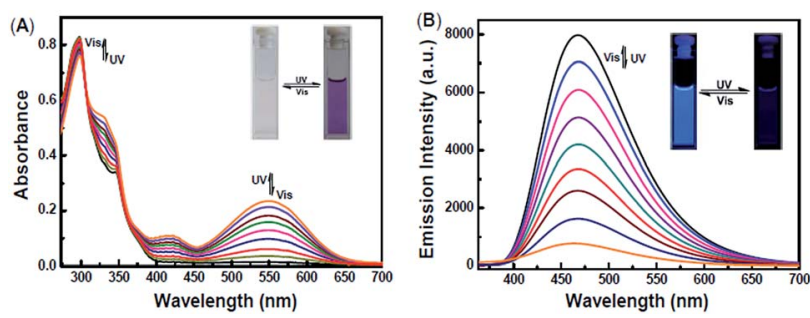

Fig. 2 Changes in the absorption and fluorescence of 10 upon alternating irradiation with UV and visible light in THF: (A) absorption spectra change $\left(2.0 \times 10^{-5} \mathrm{~mol} \mathrm{~L}^{-1}\right)$; $(B)$ fluorescence change $(2.0 \times$ $\left.10^{-5} \mathrm{~mol} \mathrm{~L}^{-1}\right)$, excited at $354 \mathrm{~nm}$. 
photoirradiation when excited at $354 \mathrm{~nm}$. Upon irradiation with 297 nm UV light, the emission peak of 10 was decreased significantly due to the formation of non-fluorescent closedring isomer 1C, which was accompanied by an obvious fluorescence intensity change from light blue to dark. In the photostationary state, the emission intensity of $\mathbf{1 0}$ was quenched to ca. $97 \%$, and the fluorescence quantum yield of 10 to $1 \mathrm{C}$ was determined to be 0.459 to 0.008 . Similarly, the fluorescence intensity of 1 could also be recovered with the irradiation of appropriate visible light $(\lambda>500 \mathrm{~nm})$.

\section{Fluorescent turn-off detection of $\mathbf{H g}^{2+}$}

The fluorescence response of 10 toward 16 different metal ions $\left(\mathrm{Hg}^{2+}, \mathrm{Cd}^{2+}, \mathrm{Zn}^{2+}, \mathrm{Mg}^{2+}, \mathrm{Ca}^{2+}, \mathrm{Ba}^{2+}, \mathrm{Cr}^{3+}, \mathrm{Al}^{3+}, \mathrm{Ni}^{2+}, \mathrm{Mn}^{2+}, \mathrm{Co}^{2+}\right.$, $\left.\mathrm{Cu}^{2+}, \mathrm{Sr}^{2+}, \mathrm{Pb}^{2+}, \mathrm{Fe}^{3+}, \mathrm{K}^{+}\right)$was measured in THF $\left(2.0 \times 10^{-5} \mathrm{~mol}\right.$ $\mathrm{L}^{-1}$ ) at room temperature. As shown in Fig. 3A, diarylethene 10 displayed a strong fluorescence with an emission of $468 \mathrm{~nm}$. The addition of 5.0 equiv. metal ion $\left(\mathrm{Cd}^{2+}, \mathrm{Zn}^{2+}, \mathrm{Mg}^{2+}, \mathrm{Ca}^{2+}\right.$, $\mathrm{Ba}^{2+}, \mathrm{Cr}^{3+}, \mathrm{Al}^{3+}, \mathrm{Ni}^{2+}, \mathrm{Mn}^{2+}, \mathrm{Co}^{2+}, \mathrm{Cu}^{2+}, \mathrm{Sr}^{2+}, \mathrm{Pb}^{2+}$ or $\left.\mathrm{K}^{+}\right)$to the solution, 10 showed no significant changes in its fluorescence, while the same amount of $\mathrm{Fe}^{3+}$ caused the fluorescence intensity to decrease by almost $30 \%$. The addition of $\mathrm{Hg}^{2+}$ into 10 resulted in the complete quench of its fluorescence intensity. The Fig. 3B shows the fluorescence color changes of $\mathbf{1 0}$ when the various metal ions added. These results indicated that $\mathbf{1 0}$ could easily discriminate $\mathrm{Hg}^{2+}$ from others metal ions.

As shown in Fig. 4, when the $\mathbf{1 0}$ was titrated with $\mathrm{Hg}^{2+}$, the fluorescence intensity was significantly decreased until 3.2 equiv. of $\mathrm{Hg}^{2+}$ were added. With further addition of $\mathrm{Hg}^{2+}$, the fluorescence intensity was then decreased slowly. When 5.0 equiv. of $\mathrm{Hg}^{2+}$ were added, the fluorescence intensity of $\mathbf{1 0}$ was almost quenched completely. The quantum yields of $\mathbf{1 0}^{\prime}$ (the complex of 10 added the $\mathrm{Hg}^{2+}$ ) from 0.459 to 0.11 were determined. Meanwhile, based on the linear Benesi-Hildebrand expression and the Stern-Volmer plot, linear relationships
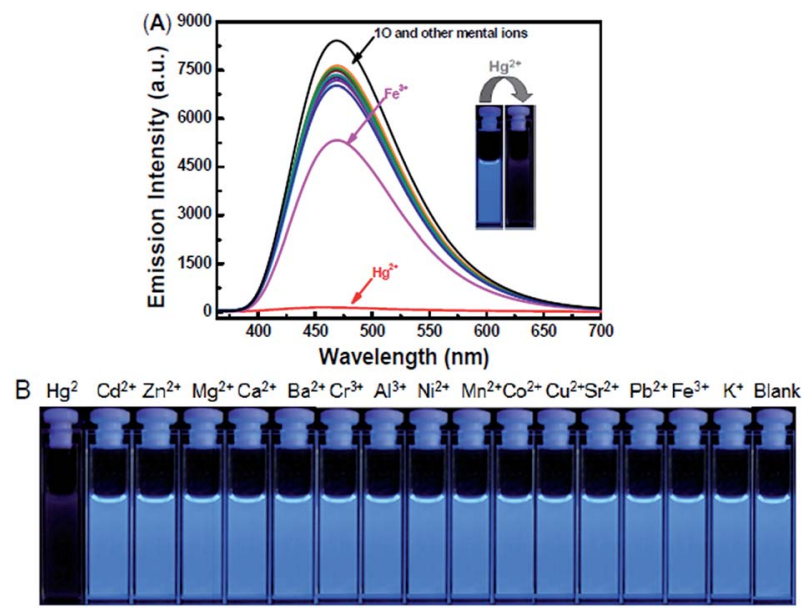

Fig. 3 Competitive changes in the fluorescence of 10 in THF $(2.0 \times$ $10^{-5} \mathrm{~mol} \mathrm{~L}^{-1}$ ) with the addition of various metal ions (5.0 equiv.): (A) emission spectral changes, (B) image of the fluorescence color changes.

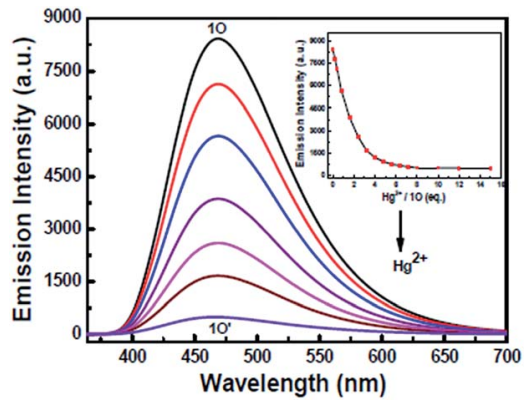

Fig. 4 Changes in the fluorescence of 10 induced by Hg${ }^{2+}$ in THF (2.0 $\times 10^{-5} \mathrm{~mol} \mathrm{~L}^{-1}$ ) and emission intensity changes of 10 induced by the addition of different equiv. of $\mathrm{Hg}^{2+}$.

between $10^{\prime}$ fluorescence at $468 \mathrm{~nm}$ and $10 /\left[\mathrm{Hg}^{2+}\right]$ were obtained. The association constant of $\mathrm{Hg}^{2+}$ binding to diarylethene 10 was found as $1.11 \times 10^{4} \mathrm{~L} \mathrm{~mol}^{-1}(R=0.99858)$. The limit of 10 as a fluorescent sensor to detect $\mathrm{Hg}^{2+}$ was $4.76 \times$ $10^{-8} \mathrm{~mol} \mathrm{~L}^{-1}$, which was determined from a plot of intensity as a function of the concentration of $\mathrm{Hg}^{2+}$ (Fig. S4 $\dagger$ ). ${ }^{50}$

Comparative, Job's plots and the ESI-MS experiments were conducted to elucidate the binding mode of $\mathbf{1 0}$ with $\mathrm{Hg}^{2+}$. The naphthol-benzothiazole moiety (NBTZ), quinolinol-benzoxazole moiety (QBOZ) and quinolinol-benzothiazole (QBTZ) moiety were synthesized to the comparative experiments and all the ${ }^{1} \mathrm{H}$ NMR, ${ }^{13} \mathrm{C}$ NMR datas were conducted. (Fig. S5 $\dagger$ ) Then, the detection to $\mathrm{Hg}^{2+}$ in THF $\left(2.0 \times 10^{-5} \mathrm{~mol} \mathrm{~L}^{-1}\right)$ of the precursor 3, NBTZ, QBOZ and QBTZ were tested. The precursor 3 and the probe NBTZ have no effect on $\mathrm{Hg}^{2+}$, the probe QBOZ and QBTZ could all be quenched by $\mathrm{Hg}^{2+}$. (Fig. $\mathrm{S}^{\dagger} \dagger$ ) These phenomenon indicated that the $\mathrm{Hg}^{2+}$ could combine the atom "N" from the quinoline, the other bridging site could not be determined. While, the same structure that contains quinolinolbenzimidazole in our earlier published paper that could not recognize $\mathrm{Hg}^{2+}{ }^{51}$ So, we think the other possible bridging site was the atom "S" from the benzothiazole. According to its ESIMS spectrometry of $\mathbf{1 0}^{\prime}$ (Fig. S7 $\dagger$ ), it had a $1: 1$ complexation stoichiometry in $\mathbf{1 0}-\mathrm{Hg}^{2+}$ complex with a peak at $\mathrm{m} / \mathrm{z} 985.3$ due to $\left[\mathbf{1 0}+\mathrm{Hg}^{2+}\right]^{+}$, another peak at $m / z 1209.9$ due to $\left[\mathbf{1 0}+\mathrm{Hg}^{2+}\right.$ $\left.+2 \mathrm{ClO}_{4}{ }^{-}+\mathrm{Na}^{+}\right]^{+}$. As shown in Fig. 5 of Job's plots, the maximum value was achieved when the molar fraction of $\left[\mathrm{Hg}^{2+}\right] /\left(\left[\mathrm{Hg}^{2+}\right]+\right.$ [10]) was about 0.5 , which further demonstrated the $1: 1$ stoichiometry between 10 with $\mathrm{Hg}^{2+}$.

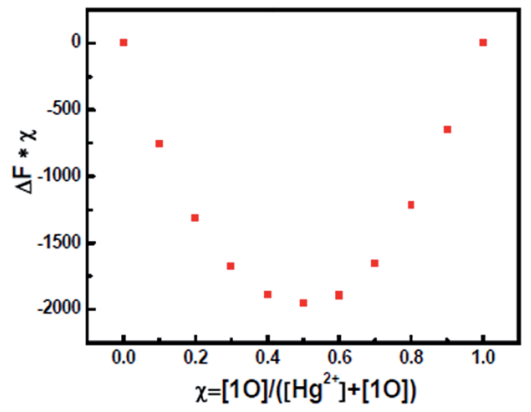

Fig. 5 Job's plot of 10 with $\mathrm{Hg}^{2+}$ 


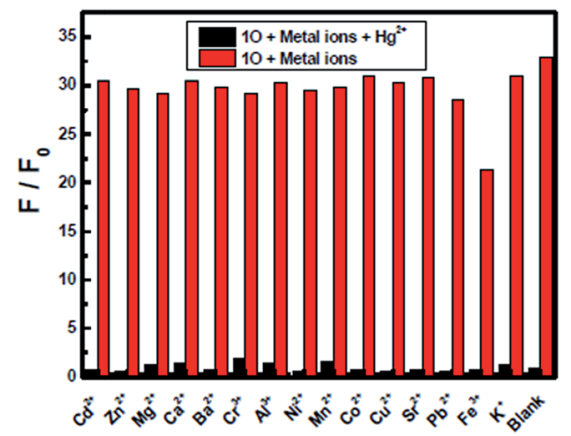

Fig. 6 Competitively fluorescent response tests of $10^{\prime}$ to various metal ions in THF $\left(2.0 \times 10^{-5} \mathrm{~mol} \mathrm{~L}^{-1}\right)$. Red bars represent the addition of 5.0 equiv. of various metal ions to the solution of 10 . Black bars represent the addition of $\mathrm{Hg}^{2+}$ (5.0 equiv.) to the above solution, respectively

In the competitive experiment, the fluorescence quenching of diarylethene 10 caused by 5.0 equiv. of $\mathrm{Hg}^{2+}$ was retained in the presence of the same concentration of other metal ions, including $\mathrm{Cd}^{2+}, \mathrm{Zn}^{2+}, \mathrm{Mg}^{2+}, \mathrm{Ca}^{2+}, \mathrm{Ba}^{2+}, \mathrm{Cr}^{3+}, \mathrm{Al}^{3+}, \mathrm{Ni}^{2+}, \mathrm{Mn}^{2+}$, $\mathrm{Co}^{2+}, \mathrm{Cu}^{2+}, \mathrm{Sr}^{2+}, \mathrm{Pb}^{2+}, \mathrm{Fe}^{3+}$ and $\mathrm{K}^{+}$. These results indicated that 10 had an excellent selectivity to $\mathrm{Hg}^{2+}$ over other metal ions (Fig. 6).

\section{Fluorescent turn-on response of $10^{\prime}$ toward Cys}

As shown in Fig. 7, studies on $\mathbf{1 0}^{\prime}$ fluorescent spectra with 17 different amino-acids, such as Cys, Gly, Ala, Val, Leu, Ile, Phe, Pro, Try, Ser, Tyr, Glu, Thr, Glu, Lys and Arg were conducted in THF. Becasue $\mathrm{Hg}^{2+}$ has high affinity towards thiol-based aminoacids, ${ }^{52-54}$ the fluorescence intensity of $\mathbf{1 0}^{\prime}$ almost recovered to the original of $\mathbf{1 0}$ only when Cys was added into the solution, and the quantum yields of $\mathbf{1 0}^{\prime}+$ Cys was measured as 0.426 , while other amino-acids did not change the emission spectra. The fluorescence recovery might be due to release of $\mathbf{1 0}$ from the $\mathbf{1 0}^{\prime}$ through the interaction of thiol-containing Cys with $\mathrm{Hg}^{2+}$. Then, others organic thiol compounds like ethylene mercaptan, 2-aminothiophenol and 2-aminoethanethiol were
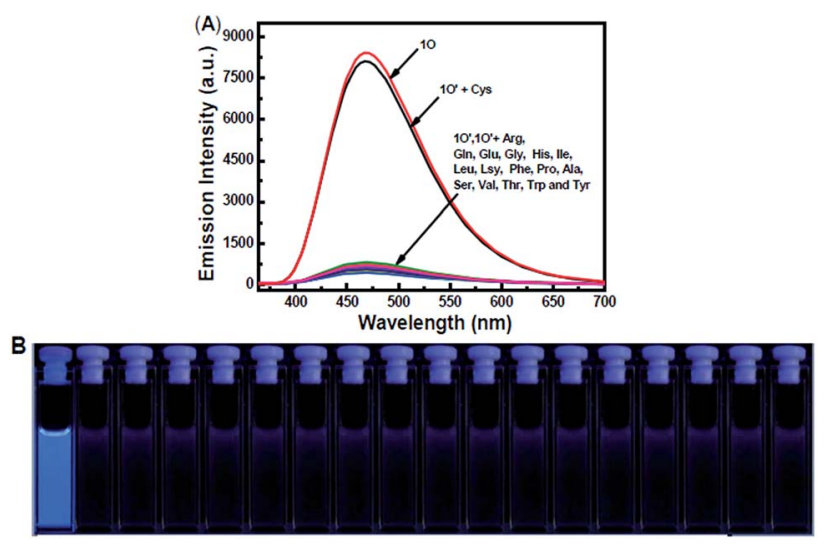

Fig. 7 Changes in fluorescence of $10^{\prime}$ induced by Cys in THF $(2.0 \times$ $10^{-5} \mathrm{~mol} \mathrm{~L}^{-1}$ ): (A) emission spectral changes; (B) image demonstrating changes in fluorescence.

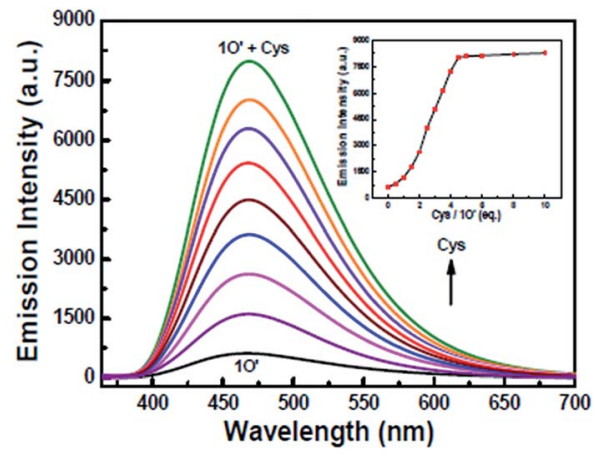

Fig. 8 Fluorescence changes of $10^{\prime}$ induced by Cys in THF $(2.0 \times$ $10^{-5} \mathrm{~mol} \mathrm{~L}^{-1}$ ) and emission intensity changes of $1 \mathrm{O}^{\prime}$ induced by different equiv. of Cys.

tested and the fluorescence could also recovery. (Fig. S8 $\dagger$ ) These results showed that $\mathbf{1 0}^{\prime}$ could be successfully utilized to sensor thiol-containing compounds with turn-on fluorescence.

As shown in Fig. 8, when Cys was added to the solution of $\mathbf{1 0}^{\prime}$, the fluorescence of the solution was enhanced rapidly. When 5.0 equiv. of Cys was added, the fluorescence recovered to the original of 10, indicating that Cys took the $\mathrm{Hg}^{2+}$ away from 10'. According to the Job's plots (Fig. 9) and ESI-MS spectrometry (Fig. S9 $\dagger$ ), the complex 10' - Cys had a $1: 2$ coordination stoichiometry. In the negative-ion mass spectrum, the peak at $\mathrm{m} / \mathrm{z} 441.4$ was assignable to $\left[2 \mathrm{Cys}+\mathrm{Hg}^{2+}+\mathrm{H}\right]^{-}$and the other peak at $m / z 785$ was assignable to 10. Similarly, according to Benesi-Hildebrand, the binding constant between $\mathbf{1 0}^{\prime}$ and Cys was $7.86 \times 10^{3} \mathrm{~L} \mathrm{~mol}^{-1}(R=0.99351)$ and the detection limit of $1^{\prime}$ was $7.06 \times 10^{-8} \mathrm{~mol} \mathrm{~L}^{-1}$ (Fig. S10 $\dagger$ ).

As shown in Fig. 10, when $\mathbf{1 0}^{\prime}$ was treated with 5.0 equiv. of Cys in the presence of the same concentration of other aminoacids, the emission enhancement caused by Cys was retained with Gly, Ala, Val, Leu, Ile, Phe, Pro, Try, Ser, Tyr, Glu, Thr, Glu, Lys, Arg and His, which indicated that any other amino acids could not interference the detection of Cys by $\mathbf{1 0}^{\prime}$ in THF.

\section{Application of 10 in logic circuits}

Since the fluorescence intensity of $\mathbf{1 0}$ could be controlled by the stimulation of UV/Vis light, $\mathrm{Hg}^{2+}$ and Cys, a combinational logic circuit could be constructed with four inputs (In1: $297 \mathrm{~nm}$ UV

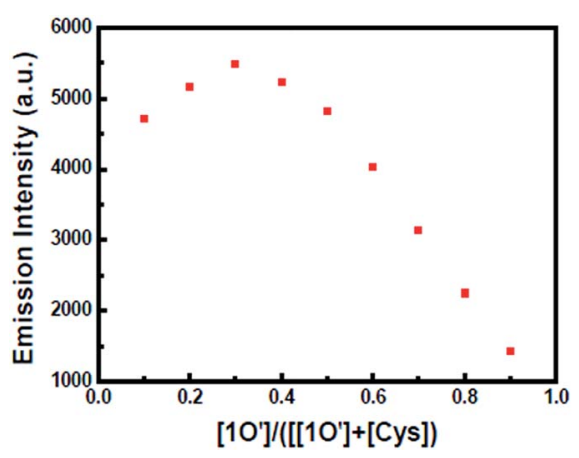

Fig. 9 Job's plot of $10^{\prime}$ with Cys. 


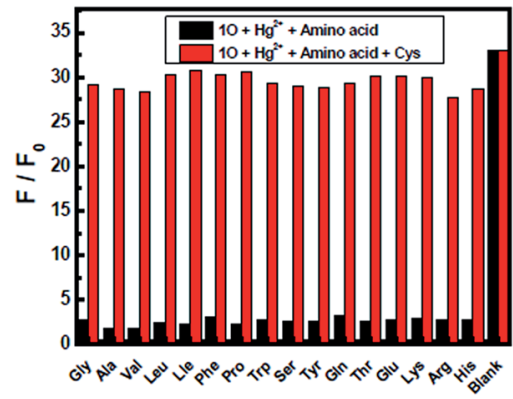

Fig. 10 Competitive tests on the fluorescent responses of $10^{\prime}+$ Cys to various amino acids in THF $\left(2.0 \times 10^{-5} \mathrm{~mol} \mathrm{~L}^{-1}\right)$. Black bars represent the addition of 5.0 equiv. of various amino acids to the $10^{\prime}$ solution. Red bars represent the addition of Cys (5.0 equiv.) to the above solution, respectively.

light, In2: $\lambda>500 \mathrm{~nm}$ visible light, In3: $\mathrm{Hg}^{2+}$ and In4: Cys) and one output signal (the change of fluorescence intensity at 468 $\mathrm{nm})$. The emission intensity of $\mathbf{1 0}$ at $468 \mathrm{~nm}$ was regarded as the initial value.

All the four inputs could be either "on" or "off" state with different Boolean values. When the emission intensity was quenched by over $50 \%$ of the initial value, the output signal could be regarded as 'off' state with a Boolean value of ' 0 '. Otherwise, it was regarded as 'on' state with a Boolean value of ' 1 '. The diarylethene 10 showed an on-off-on fluorescence switching behavior under the stimuli of different inputs. For example, when the string is ' $0,0,1$, and 0 ' the corresponding input signals of In1, In2, In3, and In4 are 'off, off, on, off'. It means that 10 was stimulated by $\mathrm{Hg}^{2+}$ and its emission intensity quenched dramatically. And the output signal was 'off' with a digit of ' 0 '. All possible strings of the three inputs were listed in Table 1 and the logic circuit corresponding to the truth table was shown in Fig. 11.

Table 1 Truth table for all possible strings of the four binary-input data and the corresponding output digit

\begin{tabular}{lllll}
\hline Input & & & & \\
\cline { 1 - 2 } In1 (UV) & In2 (Vis) & In3 $\left(\mathrm{Hg}^{2+}\right)$ & In4 (Cys) & $\begin{array}{l}\text { Output } \\
\lambda_{\mathrm{em}}{ }^{a}\end{array} 468 \mathrm{~nm}$ \\
\hline 0 & 0 & 0 & 0 & 1 \\
1 & 0 & 0 & 0 & 0 \\
0 & 1 & 0 & 0 & 1 \\
0 & 0 & 1 & 0 & 0 \\
0 & 0 & 0 & 1 & 1 \\
1 & 1 & 0 & 0 & 1 \\
1 & 0 & 1 & 0 & 0 \\
1 & 0 & 0 & 1 & 0 \\
0 & 1 & 1 & 0 & 0 \\
0 & 1 & 0 & 1 & 1 \\
0 & 0 & 1 & 1 & 1 \\
1 & 1 & 1 & 0 & 0 \\
1 & 1 & 0 & 1 & 1 \\
1 & 0 & 1 & 1 & 0 \\
0 & 1 & 1 & 1 & 1 \\
1 & 1 & 1 & 1 & 1
\end{tabular}

${ }^{a}$ The emission intensity of $\mathbf{1 0}$ at $468 \mathrm{~nm}$ was regarded as the initial value and defined as 1 , otherwise defined as 0 .

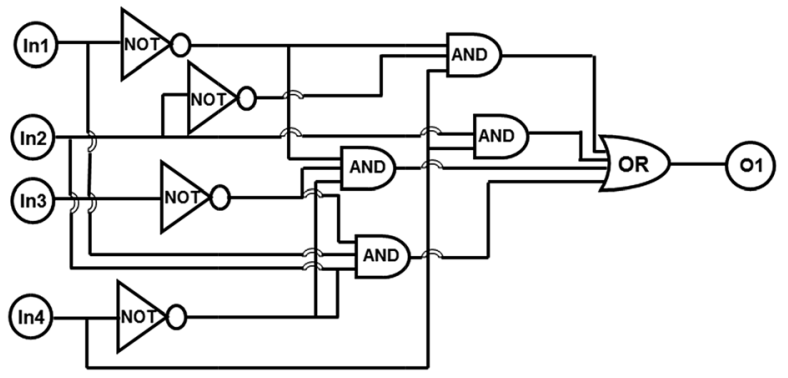

Fig. 11 Combinational logic circuits equivalent to the truth table given in Table 1: In1 (UV), In2 (Vis), In3 $\left(\mathrm{Hg}^{2+}\right), \ln 4$ (Cys).

\section{Conclusions}

In summary, a new diarylethene-based "on-off-on" fluorescence sensor for the sequential recognition of $\mathrm{Hg}^{2+}$ and Cys with very high selectivity and sensitivity was designed and synthesized successfully. When $\mathrm{Hg}^{2+}$ was added into the solution of $\mathbf{1 0}$, fluorescence of the $\mathbf{1 0}$ solution was quenched because 10 bond to $\mathrm{Hg}^{2+}$ into $\left[\mathbf{1 0}-\mathrm{Hg}^{2+}\right]\left(\mathbf{1 O}^{\prime}\right) 1: 1$ stoichiometry. When Cys was added into $1 \mathbf{1}^{\prime}$ solution, the fluorescence was enhanced significantly due to the reaction between $10^{\prime}$ and Cys in $1: 2$ stoichiometry. Based on the fact that the fluorescence of the diarylethene could be effectively modulated with the stimulation of light and chemical species, a logic circuit was also constructed successfully with the fluorescence intensity as the output signal, and UV/Vis, $\mathrm{Hg}^{2+}$ and Cys as the inputs, which should have great potentials in future fluorescent sensors for some special species.

\section{Acknowledgements}

The authors are grateful for the financial support from the National Natural Science Foundation of China (21662015, 21363009, 21362013, 51373072), the Project of Jiangxi Academic and Technological leader (20142BCB22010), and the Project of the Science Funds of Jiangxi Education Office (KJLD13069). YC2015-S392.

\section{Notes and references}

1 H. N. Kim, W. X. Ren, J. S Kim and J. Yoon, Chem. Soc. Rev., 2012, 41, 3210-3244.

2 M. Li, X. J. Zhou, W. Q. Ding, S. W. Guo and N. Q. Wu, Biosens. Bioelectron., 2013, 79, 889-893.

3 N. Zheng, Q. C. Wang, X. W. Zhang, D. M. Zheng, Z. S. Zhang and S. Q. Zhang, Sci. Total Environ., 2007, 387, 96-104.

4 J. K. Virtanen, T. H. Rissanen, S. Voutilainen and T. P. Tuomainen, J. Nutr. Biochem., 2007, 18, 75-85.

5 T. W. Clarkson, L. Magos and G. J. Myers, N. Engl. J. Med., 2003, 349, 1731-1737.

6 J. Gutknecht, J. Membr. Biol., 1981, 61, 61-66.

7 E. M. Nolan and S. J. Lippard, Chem. Rev., 2008, 108, 34433480 . 
8 Y. W. Chen, C. F. Huang, K. S. Tsai, R. S. Yang, C. C. Yen, C. Y. Yang, S. Y. Lin-Shiau and S. H. Liu, Chem. Res. Toxicol., 2006, 19, 1080-1085.

9 P. Holmes, K. A. F. James and L. S. Levy, Sci. Total Environ., 2009, 408, 171-182.

10 M. Ghaedi, M. R. Fathi, A. Shokrollahi and F. Shajarat, Anal. Lett., 2006, 39, 1171-1185.

11 T. Matousek, A. Z. Hernández, M. Svoboda, L. Langrová, B. M. Adair, Z. Drobná, D. J. Thomas, M. Styblo and J. Dedina, Spectrochim. Acta, Part B, 2008, 63, 396-406.

12 X. Y. Jia, Y. Han, X. L. Liu, T. C. Duan and H. T. Chen, Spectrochim. Acta, Part B, 2011, 66, 88-92.

13 Y. L. Feng, H. W. Chen and H. Y. Chen, J. Anal. Chem., 1998, 361, 155-157.

14 B. Han, J. Yuan and E. Wang, Anal. Chem., 2009, 81, 55695573.

15 B. Cao, C. Yuan, B. Liu, C. Jiang, G. Guan and M. Y. Han, Anal. Chim. Acta, 2013, 786, 146-152.

16 C. Wang, D. Zhang, X. Huang, P. Ding, Z. Wang, Y. Zhao and Y. Ye, Sens. Actuators, B, 2014, 198, 33-40.

17 D. H. Kim, J. Seong, H. Lee and K. H. Lee, Sens. Actuators, B, 2014, 196, 421-428.

18 M. Li, Q. Wang, X. Shi, L. A. Hornak and N. Wu, Anal. Chem., 2011, 83, 7061-7065.

19 R. M. Kong, X. B. Zhang, L. L. Zhang, X. Y. Jin, S. Y. Huan, G. L. Shen and R. Q. Yu, Chem. Commun., 2009, 5633-5635.

20 M. Hollenstein, C. Hipolito, C. Lam, D. Dietrich and D. M. Perrin, Angew. Chem., Int. Ed., 2008, 47, 4346-4350.

$21 \mathrm{H}$. Urata, E. Yamaguchi, T. Funai, Y. Matsumura and S. I. Wada, Angew. Chem., 2010, 122, 6666-6669.

22 Y. Zhao and Z. Zhong, J. Am. Chem. Soc., 2006, 128, 99889989.

23 S. Seshadri, A. Beiser, J. P. Selhub, F. I. Jacques, H. Rosenberg, R. B. D. Agostino, P. W. Wilson and P. A. N. Wolf, N. Engl. J. Med., 2002, 346, 476-483.

24 S. A. Lee, J. J. Lee, J. W. Shin, K. S. Min and C. Kim, Dyes Pigm., 2015, 116, 131-138.

25 Y. Yang, F. J. Huo, C. Yin, J. Chao and Y. Zhang, Dyes Pigm., 2015, 114, 105-109.

26 C. Hwang, A. J. Sinskey and H. F. Lodish, Science, 1992, 257, 1496-1502.

27 L. Wang, Q. Zhou, B. Zhu, L. Yan, Z. Ma, B. Du and X. Zhang, Dyes Pigm., 2012, 95, 275-279.

28 F. Jalilehvand, B. O. Leung, M. Izadifard and E. Damian, Inorg. Chem., 2006, 45, 66-73.

29 J. S. Wu, R. L. Sheng, W. M. Liu, P. F. Wang, J. J. Ma, H. Y. Zhang and X. Q. Zhuang, Inorg. Chem., 2011, 50, 6543-6551.
30 G. Mcdonnell and D. A. Russell, Clin. Microbiol. Rev., 1999, 12, 147-157.

31 S. Shahrokhian, Anal. Chem., 2001, 73, 5972-5978.

32 C. Jacob, G. I. Giles, N. M. Giles and H. Sies, Angew. Chem., Int. Ed., 2003, 42, 4742-4758.

33 Z. Li, Y. Wang, Y. N. Ni and S. Kokot, Sens. Actuators, B, 2015, 207, 490-497.

34 B. L. Feringa, Molecular Switches, 2001.

35 V. Balzani, M. Venturi and A. Cred, Molecular Devices and Machines, 2003.

36 I. Willner, Acc. Chem. Res., 1997, 30, 347-356.

37 K. Higashiguchi, K. Matsuda, N. Tanifuji and M. Irie, J. Am. Chem. Soc., 2005, 127, 8922-8923.

38 B. M. Neilson and C. W. Bielawski, J. Am. Chem. Soc., 2012, 134, 12693-12699.

39 S. Kawata and Y. Kawata, Chem. Rev., 2000, 100, 1777-1788.

40 Y. Nakayama, K. Hayashi and M. Irie, J. Org. Chem., 1990, 55, 2592-2596.

41 F. Duan, G. Liu, P. Liu, C. B. Fan and S. Z. Pu, Tetrahedron, 2016, 72, 3213-3220.

42 S. J. Xia, G. Liu and S. Z. Pu, J. Mater. Chem. C, 2015, 3, 4023.

43 S. Q. Cui, Z. Y. Tian, S. Z. Pu and Y. F. Dai, RSC Adv., 2016, 6, 19957.

44 Q. Zou, J. Y. Jin, B. Xu, L. Ding and H. Tian, Tetrahedron, 2011, 67, 915-921.

45 C. H. Zheng, S. Z. Pu, G. Liu, B. Chen and Y. F. Dai, Dyes Pigm., 2013, 98, 280-285.

46 S. Z. Pu, L. L. Ma, G. Liu, H. C. Ding and B. Chen, Dyes Pigm., 2015, 113, 70-77.

47 Z. X. Li, L. Y. Liao, W. Sun, C. H. Xu, C. Zhang, C. J. Fang and C. H. Yan, J. Mater. Chem. C, 2008, 112, 5190-5196.

48 L. Yuan, W. Y. Lin, Z. M. Cao, J. L. Wang and B. Chen, Chem.Eur. J., 2012, 18, 1247-1255.

49 M. Irie, T. Lifka, S. Kobatake and N. Kato, J. Am. Chem. Soc., 2000, 122, 4871-4876.

50 S. Y. Tao, Y. Wei, C. Wang and B. J. Ding, RSC Adv., 2014, 4, 46955-46961.

51 G. Li, G. Liu, D. B. Zhang and S. Z. Pu, Tetrahedron, 2016, 72, 6390-6396.

52 Y. Y. Fu, H. X. Li, W. P. Hu and D. B. Zhu, Chem. Commun., 2005, 3189-3191.

53 N. Shao, J. Y. Jin, S. M. Cheung and R. H. Yang, Angew. Chem., Int. Ed., 2006, 45, 4944-4948.

54 Z. Q, Guo, S. W. Nam, S. S. Park and J. Y. Yoon, Chem. Sci., 2012, 3, 2760-2765. 